\title{
Application of PBL-Based Situational Simulation Teaching in Surgical Nursing Experimental Teaching
}

\author{
Liqing Li1 ${ }^{*}$, Xianjiu Liao ${ }^{*}$, Xuebin Li ${ }^{1}$, Jihua Wei², Xiaozhen Lin², Yan'E Zhou1, Longjian Huang1, \\ Qianli Tang1\#, Qianying Luo" ${ }^{1 \#}$
}

${ }^{1}$ Youjiang Medical University for Nationalities, Baise, China

${ }^{2}$ Youjiang Medical University for Nationalities Affiliated Hospital, Baise, China

Email: ${ }^{* 1265297183 @ q q . c o m, ~}{ }^{\star}$ htmgx@ymcn.edu.cn

How to cite this paper: Li, L. Q., Liao, X. J., Li, X. B., Wei, J. H., Lin, X. Z., Zhou, Y. E., Huang, L. J., Tang, Q. L., \& Luo, Q. Y. (2021). Application of PBL-Based Situational Simulation Teaching in Surgical Nursing Experimental Teaching. Creative Education, $12,817-823$

https://doi.org/10.4236/ce.2021.124058

Received: March 9, 2021

Accepted: April 19, 2021

Published: April 22, 2021

Copyright (๑) 2021 by author(s) and Scientific Research Publishing Inc. This work is licensed under the Creative Commons Attribution International License (CC BY 4.0).

http://creativecommons.org/licenses/by/4.0/

\begin{abstract}
Objective: To observe the application effect of PBL-based situational simulation teaching in surgical nursing experimental teaching. Methods: 120 nursing students in our school who participated in the internship from August 2019 to August 2020 were randomly divided into PBL group, situational simulation group, $\mathrm{PBL}+$ situational simulation group and traditional teaching group, with 30 students in each group. And then the teaching effects of the students in each group were compared. Results: Students in the PBL + situational simulation teaching group were more satisfied with teachers' teaching, teaching methods and pleasant classroom atmosphere than those in the traditional teaching mode and the PBL or situational simulation teaching group, and the same was true in the examination results. The difference was statistically significant $(P<0.05)$. Conclusion: PBL combined with situational simulation teaching method can significantly improve the teaching level of surgical nursing experiment and students' learning efficiency.
\end{abstract}

\section{Keywords}

PBL Teaching, Situational Simulation, Surgical Nursing, Experimental Teaching

\section{Introduction}

Surgical nursing has always been the key for rehabilitation of patients with surgical diseases, so it is particularly important to improve the surgical nursing level of health workers. At present, the teaching of surgical nursing has been based on the traditional teaching model: teacher-centered, supplemented by multimedia.

${ }^{\star}$ These authors contributed equally to this work.

"Correspongding author. 
However, this boring teaching model leads to students' low learning efficiency. Based on this, many teachers have proposed the problem-based teaching method (PBL) combined with situational simulation.

Situational simulation, different from traditional teaching, is a more effective and interesting teaching method. Teachers set up teaching situations according to the actual content, teaching tasks and teaching objectives in the teaching process to guide students to play some roles in the situations and then simulate the process of situations (Wang, 2010); However, PBL mode is a relatively perfect teaching method to set up learning situations, that is, a question-based, student-centered, teacher-led and group-discussion teaching method (Wang, Duan, Wang, et al., 2010). The PBL-based situational simulation teaching takes the specific questions in situations as the driving force for research and learning. It is thus quite operable and interesting and can greatly improve the learning efficiency of students. Therefore, the model enjoys great popularity in surgical nursing experimental teaching. The surgical nursing teaching and research section of our school adopt the PBL-based situational simulation teaching to carry out experimental teaching. The report is as follows:

\section{Data and Methods}

\subsection{General Data}

According to random number table, 120 nursing undergraduates in our school who participated in the internship from August 2019 to August 2020 were selected as our subjects, and they were grouped in accordance with the completely randomized grouping: $\mathrm{PBL}$, situational simulation, $\mathrm{PBL}+$ situational simulation and traditional teaching, with 30 students in each group. The PBL group consisted of 8 males and 22 females, aged 20 - 21 years; The situational simulation group consisted of 6 males and 24 females, aged 20 - 21 years; The PBL+ situational simulation group consisted of 7 males and 23 females, aged 20 - 22 years; The traditional teaching group consisted of 6 males and 24 females, aged $19-21$ years. There was no difference of statistical significance among the general data of the students in each group, such as age and sex $(P>0.05)$, but they are comparable among groups.

\subsection{Methods}

\subsubsection{Teaching Method in PBL Group}

PBL teaching method applies. 30 trainee nurses were randomly divided into 5 groups according to the random number table, with 6 nurses in each group. 3 class hours was assigned to each surgical experimental teaching project, and 3 hours into 4 time periods for teaching: The first phase, organization and preparation phase, lasting for $30 \mathrm{~min}$, required teachers to set up relevant questions according to the teaching content and guide students to conduct group discussion around the questions, design the experimental steps, assume the problems that may occur or results that they may encounter in the process, and further re- 
view relevant information; In the second phase, practical operation phase, lasting for 1 hour, the students carried out the experimental operation according to the contents and results discussed in the first phase, and solved the problems encountered in the experimental operation under the guidance of teachers; In the third phase, known as summary phase lasting for $15 \mathrm{~min}$, the students summarized the advantages and disadvantages of the experiment design and the key and difficult points in the experimental process; In the fourth phase, advance design phase lasting for $15 \mathrm{~min}$, teachers designed clinical situations in advance based on the next teaching content and posed questions to actuate students to think about them before the next teaching activity (Wang, 2016).

\subsubsection{Teaching Method of the Situational Simulation Group}

The teaching activities were divided into three steps: organization and preparation, situational simulation and summary and comment $(\mathrm{Wu}$, Wang, \& $\mathrm{Li}$, 2019). 30 interns were randomly divided into 5 groups according to the random number table, with 6 interns in one group. 3 class hours were assigned to each surgical experimental teaching project, and 3 hours into 3 time periods for teaching: In the first phase, organizational preparation phase, which lasted for $30 \mathrm{~min}$, teachers distributed relevant individual patient data and introduced relevant knowledge backgrounds, so that students can clearly understand the learning contents and conceive situational scripts to design their experiments (He, 2019); In the second phase, situational simulation phase lasting for 1 hour, the students started their practice. In each group, one student with certain performance ability was selected to act as the patient, one to act as the patient's family, and one to record the problems during the experiment. The other three were selected to inquire and care for the patients respectively. The third phase was about summary and comment, which lasted for $30 \mathrm{~min}$. The teachers summarized the problems the students encountered in their study, made targeted comments and then put forward relevant improvement measures.

\subsubsection{Teaching Method of PBL+ Situational Simulation Group}

The combination of PBL and situational simulation applied in teaching. 30 interns were randomly divided into 5 groups according to the random number table, with 6 interns in one group. 3 class hours were assigned to each surgical experimental teaching project. First of all, teachers selected relevant cases according to the teaching contents and design PBL teaching plan in detail ahead of time. Before class, teachers printed the contents, process and role-playing in situational simulation of the teaching plan designed in advance and distributed them to students. Then, based on the principle of voluntariness, students selected appropriate roles to play. At the same time, in the process of situational simulation, students asked questions and discussed based on the changing situation. Teachers need to listen to and record the discussion contents of students in each group, and finally summarize and conclude the whole lesson (Wang \& Cui, 2017). 


\subsubsection{Teaching Method of the Traditional Teaching Group}

30 interns were gathered in the same classroom. The teacher explained on the platform, supplemented by multimedia demonstration, and the students are passive receivers. The explanation contents were consistent with those of the above groups.

\subsection{Observation Indicators and Teaching Evaluation Standards}

Questionnaire survey was conducted to investigate teaching satisfaction, including three aspects: satisfaction of teachers' teaching, satisfaction of teaching methods and satisfaction of pleasant atmosphere in class. Each of the three options was divided into three grades: excellent, good and bad (Wang \& Cui, 2017); Students' learning effect was evaluated through their specialized theoretical examination and examination of operating skills.

\subsection{Statistical Method}

SPSS 18.0 statistical analysis software package was used for data processing. $\mathrm{n} / \%$ represented counting data, tested by $\chi^{2} ; \bar{X} \pm s$ represented the measurement data, and one-way ANOVA method is used. If $P<0.05$, the difference was statistically significant.

\section{Results}

\subsection{Comparison of Interns' Satisfaction with Teaching in Each Group}

The survey of teaching satisfaction of each group showed that the students in $\mathrm{PBL}+$ situational simulation teaching group were more satisfied with teachers' teaching, teaching methods and pleasant atmosphere in class than the students in other groups, and the difference was statistically significant $(P<0.05$, see Table 1).

\subsection{Comparison of Examination Results among the Students of Each Group}

The examinations showed that the average score of students' theoretical evaluation scores in the PBL+ situational simulation teaching group was (90.66 \pm 0.98$)$, and the average score of operating skills test was $(90.64 \pm 2.45)$, significantly better than the traditional teaching mode and PBL teaching or situational simulation teaching alone. The difference was statistically significant $(P<0.05)$. Both the PBL group and the situational simulation group were superior to the traditional teaching group, and the difference was statistically significant $(P<0.05)$ (see Table 2).

\section{Discussion}

Surgical Nursing is a practical and applicable course. Surgical nursing knowledge and skills are the foundation of surgical nurses' post competency and the core of 
Table 1. Comparison of teaching satisfaction of the students $(n=30, n / \%)$.

\begin{tabular}{|c|c|c|c|c|c|c|c|c|c|}
\hline \multirow{2}{*}{ Group } & \multicolumn{3}{|c|}{ Satisfaction of teachers' teaching } & \multicolumn{3}{|c|}{ Satisfaction of teaching methods } & \multicolumn{3}{|c|}{ Satisfaction of pleasant atmosphere in class } \\
\hline & Excellent & Good & Bad & Excellent & Good & $\mathrm{Bad}$ & Excellent & Good & Bad \\
\hline PBL Group & $11 / 36.67^{*}$ & $12 / 40.00$ & $7 / 23.33^{*}$ & $12 / 40.00^{*}$ & $13 / 43.33$ & $5 / 16.67^{*}$ & $12 / 40.00^{*}$ & $15 / 50.00^{*}$ & $3 / 10.00^{*}$ \\
\hline $\begin{array}{l}\text { Situational } \\
\text { simulation group }\end{array}$ & $10 / 33.33^{*}$ & $12 / 40.00$ & $8 / 26.67^{*}$ & $11 / 36.66^{*}$ & $14 / 46.67$ & $5 / 16.67^{*}$ & $13 / 43.33^{*}$ & $14 / 46.67^{*}$ & $3 / 10.00^{*}$ \\
\hline $\begin{array}{l}\text { PBL+ Situational } \\
\text { Simulation Group }\end{array}$ & $18 / 60.00^{*}$ & $10 / 33.33^{*}$ & $2 / 6.67^{*}$ & $21 / 70.00^{*}$ & $8 / 26.67^{*}$ & $1 / 3.33^{*}$ & $23 / 76.67^{*}$ & $7 / 23.33$ & $0 / 0^{*}$ \\
\hline $\begin{array}{l}\text { Traditional } \\
\text { teaching group }\end{array}$ & $4 / 13.33$ & $15 / 50.00$ & $11 / 36.67$ & $4 / 13.33$ & $12 / 40.00$ & $14 / 46.67$ & $2 / 6.67$ & $10 / 33.33$ & $18 / 60.00$ \\
\hline
\end{tabular}

Note: Data with * indicate that they were compared with the traditional teaching group, $P<0.05$.

Table 2. Comparison of theoretical examination scores and operating skills examination results of the students in each group $(\mathrm{n}=$ 30, $\bar{X} \pm \mathrm{S}$, Points).

\begin{tabular}{|c|c|c|c|c|}
\hline Results & PBL group & Situational simulation group & Traditional teaching group & PBL+ Situational Simulation Group \\
\hline $\begin{array}{c}\text { Theoretical } \\
\text { examination results }\end{array}$ & $77.76 \pm 1.97^{\star}$ & $76.70 \pm 2.40^{*}$ & $70.06 \pm 2.09^{\triangle \boldsymbol{\Lambda}}$ & $90.66 \pm 0.98^{\star \Delta}$ \\
\hline $\begin{array}{l}\text { Examination results } \\
\text { of operating skills }\end{array}$ & $79.68 \pm 1.20^{\star}$ & $80.66 \pm 2.56^{\star}$ & $71.23 \pm 3.68^{\triangle \Delta}$ & $90.64 \pm 2.45^{\star^{\triangle} \boldsymbol{\Lambda}}$ \\
\hline
\end{tabular}

Note: Data with ${ }^{*}$ indicate that they were compared with the traditional teaching group, $P<0.05$; Data with ${ }^{\Delta}$ indicate that they were compared with the traditional teaching group, $P<0.05$; Data with $\Delta$ indicate that they were compared with the situational simulation group, $P<0.05$.

the course, and experimental teaching is one of the main ways for students to master skills. In the past, the traditional teaching methods were generally used in surgical nursing experimental courses. For example, the teacher explained and demonstrated the operation purpose, use of instruments, experimental model, and operation precautions of surgical nursing experiment, after which finished, the students were asked to simulate by themselves. This single teaching method simply lays emphasis on the students' familiarity with and mastery of the experimental steps, and lacks the sense of substitution of communication between nurses and patients clinically. The boring teaching method that is single and passive and dull classroom atmosphere leads to students' lacking of interest and undesirable mastery of knowledge and skills.

Through the PBL-based situational simulation teaching, by the pattern of "situation-task-question" (Dang \& Ren, 2020), the problems raised by students in learning are effectively combined with the situational simulation. This process firmly focuses on the principle of "students as the main part, teachers as the leading factor, and cases as the main line". The learning enthusiasm of students is fully mobilized, thus increasing the interaction between teachers and students, improving the learning efficiency of students, and at the same time, cultivating the teamwork ability and communication competence among students. It is a brand-new teaching mode and will become the mainstream mode of medical education in the future. Based on the "situation-task-question" mode, PBL + situational simulation teaching is guided by meaningful practical questions. The role play of "nurse", "patient" and "relatives of the patients" according to the 
cases also reflects the diversified ideological and political education of the course. Through role-playing, students can perceive the warmth of the medicine science, feel the true nature of life, experience valued responsibility, and students' spirit of healing the wounded and rescuing the dying, respecting and protecting life, and being willing to contribute can be cultivated, and the knowledge, skills and quality of surgical nursing can be effectively connected with their posts. Many higher teaching researches have indicated that (Dang \& Ren, 2020; Huang, Li, \& Fan, 2020; Zeng, 2019), the PBL teaching method combined with the situational simulation teaching can significantly improve students' knowledge mastery, cooperation ability, innovation ability, practical ability, clinical confidence and other aspects.

This study showed that the phenomenon of "one person alone has the say" by teachers was changed in surgical nursing experimental class, and instead, students learned in group. The PBL + situational simulation teaching was adopted including organizing related cases, simulating situations, asking questions, discussing in groups, teachers' summarizing, as a result of which, the students were more satisfied with teachers' teaching, teaching methods, teaching methods and pleasant atmosphere in class than the students in the other groups (PBL teaching, situational simulation teaching and traditional teaching); The teaching mode of role-playing fully mobilized students' enthusiasm for active learning of skills and knowledge, and as a result, students' theoretical evaluation results and average score in examination of operating skills were higher than those of the students in other groups. Under the background of "Double First Class University Plan", in recent years, the nursing college of our school, attaching great importance to the experimental teaching of surgical nursing, has set up a practical training workshop for surgical nursing skills simulation, which integrates practical training, advanced artificial intelligence simulation and virtual simulation functions, and has a real professional atmosphere. For example, in 2019, the Teaching and Research Section of Surgical Nursing built a Project of Practical Experiment and Train of Virtual Simulation Chest Injury (which has been accessible on the national platform of Experimental Space), which was rated as the first-class undergraduate course of the autonomous region and won the first prize in the informatization education teaching competition among the college and universities in Guangxi. It provides students with a class on the air available 24 hours a day and a real environment for PBL-based situational simulation teaching, thus greatly improving the quality of practical training. However, in the course of research, the author discovered that there are some difficulties in the full implementation of this teaching method, mainly as follows: First of all, PBL-based situational simulation teaching requires students to put in a lot of time and energy, which will increase learning burden of students whose learning tasks are already heavy. Secondly, this teaching method is more suitable for classes with fewer students, while the school has limited teachers and cannot take into account the huge group of students. Thirdly, in the process of situational simulation, a certain investment in equipment will increase the cost of our 
school. Therefore, in the future process of teaching, we should focus on solving above shortcomings and make them develop better.

\section{Fund Project}

Construction project of case bank for professional degree postgraduate teaching in Youjiang Medical University for Nationalities (Project Name: Case Bank Construction of Surgery Teaching); Undergraduate Teaching Reform Project of Guangxi Higher Education (Project No.: 2019JGB308, 2018JGA237); Innovation Project of Guangxi Postgraduate Education (Project No.: JGY2021219).

\section{Conflicts of Interest}

The authors declare no conflicts of interest regarding the publication of this paper.

\section{References}

Dang, L. J., \& Ren, X. Y. (2020). The Application of PBL Combined Situational Simulation Teaching Method in Practical Courses. Journal of Weinan Normal University, 35, 13-18.

He, X. X. (2019). Application of Situational Simulation Teaching Method in Nursing Teaching of Intern Nurses in Emergency Department. China Higher Medical Education, No. 2, 115+147.

Huang, H., Li, X., \& Fan, S. (2020). Application of PBL Combined with Situational Simulation in Clinical Teaching of Tumor Nursing. Shanxi Medical Journal, 49, 3152-3153.

Wang, H. (2010). Application of Situational Simulation Combined with PBL Model in Orthopedic Teaching. Education for Chinese After-School, No. 8, 180-181.

Wang, S., Duan, C. Y., Wang, Q., et al. (2010). Application of PBL Model in Surgical Experimental Teaching. Research in Medical Education, 9, 1483-1485.

Wang, W., \& Cui, Y. (2017). Application Analysis of Situational Simulation Combined with PBL Model in Orthopedic Teaching. Clinical Research and Practice, 2, 197-198.

Wang, Y. M. (2016). Application and Effect Evaluation of PBL Model in Surgical Experimental Teaching. Chinese Journal of Medical Guide, 18, 427-428.

Wu, L. S., Wang, X., \& Li, Y. (2019). Application and Practice of Situational Simulation Teaching Method in Stratified Training of Nurses in Primary Hospitals. Smart Healthcare, No. 19, 28-29.

Zeng, L. H. (2019). Application of PBL Combined with Situational Simulation in Experimental Teaching of Obstetrics and Gynecology. Guangdong Vocational Technical Education and Research, No. 2, 168-169. 